\title{
A Genomic Scan for Age at Onset of Alzheimer's Disease in 437 Families From the NIMH Genetic Initiative
}

\author{
M. Ryan Dickson ${ }^{1,}{ }^{*}$, Jian $\mathrm{Li}^{1}$, Howard W. Wiener ${ }^{1}$, Rodney T. Perry ${ }^{1}$, Deborah Blacker ${ }^{2,3}$, \\ Susan S. Bassett ${ }^{4}$, and Rodney C.P. Go ${ }^{1}$ \\ ${ }^{1}$ Department of Epidemiology and International Health, The University of Alabama at Birmingham, \\ Birmingham, Alabama ${ }^{2}$ Gerontology Research Unit, Department of Psychiatry, Massachusetts General \\ Hospital, Harvard Medical School, Charlestown, Massachusetts ${ }^{3}$ Department of Epidemiology, Harvard \\ School of Public Health, Boston, Massachusetts ${ }^{4}$ Department of Psychiatry and Behavioral Sciences, Johns \\ Hopkins University Medical Institutions, Baltimore, Maryland
}

\begin{abstract}
We performed linkage analysis for age at onset (AAO) in the total Alzheimer's disease (AD) NIMH sample ( $\mathrm{N}=437$ families). Families were subset as late-onset ( 320 families, $\mathrm{AAO} \geq 65$ ) and early/ mixed (117 families, at least 1 member with $50<\mathrm{AAO}<65$ ). Treating AAO as a censored trait, we obtained the gender and $A P O E$ adjusted residuals in a parametric survival model and analyzed the residuals as the quantitative trait (QT) in variance-component linkage analysis. For comparison, AAO-age at exam (AAE) was analyzed as the QT adjusting for affection status, gender, and APOE. Heritabilities for residual and AAO-AAE outcomes were $66.3 \%$ and $74.0 \%$, respectively for the total sample, $56.0 \%$ and $57.0 \%$ in the late-onset sample, and $33.0 \%$ for both models in the early/ mixed sample. The residual model yielded the largest peaks onchromosome 1 with LOD $=2.0$ at 190 $\mathrm{cM}$ in the total set, $\mathrm{LOD}=1.7$ at $116 \mathrm{cM}$ on chromosome 3 in the early/mixed subset, and LOD = 1.4 at 71 and $86 \mathrm{cM}$, respectively, on chromosome 6 in the late-onset subset. For the AAO-AAE outcome model the largest peaks were identified on chromosome 1 at $137 \mathrm{cM}(\mathrm{LOD}=2.8)$ and chromosome 6 at $69 \mathrm{cM}(\mathrm{LOD}=2.3)$ and $86 \mathrm{cM}(\mathrm{LOD}=2.2)$ all in the late-onset subset. Additional peaks with $L O D \geq 1$ were identified on chromosomes 1, 2, 3, 6, 8, 9, 10, and 12 for the total sample and each subset. Results replicate previous findings, but identify additional suggestive peaks indicating the genetics of $\mathrm{AAO}$ in $\mathrm{AD}$ is complex with many chromosomal regions potentially containing modifying genes.
\end{abstract}

\section{Keywords}

Alzhiemer's disease; censored quantitative trait; variance-component linkage analysis

\section{INTRODUCTION}

\begin{abstract}
Alzheimer's disease (AD) is an age-related neurodegenerative disorder. Based on the age at onset (AAO), it can be categorized into early-onset $\mathrm{AD}(\mathrm{EOAD}, \mathrm{AAO}<65)$ and late-onset $\mathrm{AD}$ ( $\mathrm{LOAD}, \mathrm{AAO} \geq 65$ ).EOAD constitutes less than $5 \%$ of all AD cases, is mainly caused by mutations in three genes (APP,PSEN1, and PSEN2) and is known to be transmitted as a Mendelian autosomal dominant trait [Tanzi, 1999; Rocchi et al., 2003; Bertram and Tanzi,
\end{abstract}

*Correspondence to: M. Ryan Dickson, MS, Department of Epidemiology, The University of Alabama at Birmingham, Ryals 230N, 1665 University Blvd, Birmingham, AL 35294-0001. E-mail: dicksonr@uab.edu. 
2004]. The vast majority of AD cases lack a clear mode of inheritance and have a complex etiology that involves multiple genes and a host of environmental factors. The only confirmed genetic risk factor is the $\varepsilon 4$ allele of the APOE gene ( $\varepsilon 4$ ) that decreases the AAO in a dosedependent manner, with the maximal effect observed before age 70 [Corder et al., 1993; Bickeboller et al., 1997; Blacker et al., 1997; Farrer et al., 1997; Daw et al., 2000; Khachaturian et al., 2004]. Established host and environmental risk factors include female gender and lower education [Kim et al., 2005].

Examination of AD AAO may well shed light on the etiologic complexity of AD. Although there is overlap in contributing genes as risk of AD increases with age, AD AAO is considered to be distinct from $\mathrm{AD}$ risk and it is important to identify genes that play a role in this phenotype [Hagnell et al., 1992; Miech et al., 2002]. Interestingly, one recent study demonstrated the importance of AAO in dissecting the genetic complexity of AD when they showed SNPs in different candidate genes were associated with $\mathrm{AD}$ in distinct decades of life in a case control set [Beyer et al., 2005]. Specifically, if we can clarify the genetics of AAO of AD and develop treatments based on these findings the disease may potentially be delayed and moved out of the normal lifespan.

In an oligogenic segregation analysis, Daw et al. [2000] have estimated that in addition to the $A P O E$ gene, there are at least four other loci with similar or greater contribution to the variance in the AAO of LOAD. Using AAO as the trait, another group identified several suggestive linkage regions (LOD > 1.0) on chromosomes 4, 6, 8, 10,13, and 18 [Li et al., 2002]. Those studies demonstrated that like risk for $\mathrm{AD}, \mathrm{AAO}$ of $\mathrm{AD}$ is also under the influence of complex genetic factors.

There is a growing interest in studying AAO as a censored outcome in linkage analysis. This allows full use of the information contained in AAO for the affected individuals and age at exam (AAE) for their unaffected relatives who are considered to be at risk for developing $\mathrm{AD}$, thus providing more information to identify AAO quantitative trait loci (QTL) in linkage analysis [Yoo et al., 2001]. A number of linkage models have been proposed for censored traits. One family of methods adapts the semi-parametric survival models to include multivariate random effects or frailty to account for familial dependence, which can better accommodate right-censored survival traits such as AAO [Scurrah et al., 2000; Li, 2002;Pankratz etal., 2005]. One of these most recently developed frailty methods include a random effects Cox proportional hazards model with Gaussian random effects based on a Laplace approximation [Pankratz et al., 2005]. However, the computational complexity of these methods and the specific model assumptions have limited the general use of these methods. This has motivated researchers to search for methods with fewer restrictions and assumptions that can utilize existing software.

One such method, the residual statistic approach, obtains residuals from a survival model and then uses these as the quantitative trait for linkage analysis within standard genetic analysis software such as SOLAR, GENEHUNTER, or MERLIN [Kruglyak et al., 1996; Almasy and Blangero, 1998; Abecasis et al., 2002]. More importantly, simulation analyses have demonstrated that the residual statistic approach has power similar to that of the latest random effect Cox proportional hazard model [Yoo et al., 2001; Pankratz et al., 2005]. An additional advantage to this approach is the use of reliable and easy to implement standard linkage software, which produces results that can be easily compared with other published reports using the same models and software.

The current study adopted the AAO residual statistics approach in a variance-component linkage analysis. Treating AAO as a censored quantitative trait, we obtained the gender and $\varepsilon 4$ covariate-adjusted residuals in a parametric survival model and then analyzed the residuals 
as the quantitative trait in SOLAR. For comparison, AAO-AAE was analyzed as a quantitative trait in SOLAR with affection status, gender, and $\varepsilon 4$ allele dosage as covariates. The results of a genome scan for $\mathrm{AD}$ risk in this same population are detailed elsewhere and comparisons between the present study and this one are made [Blacker et al., 2003]. The consistencies of the two linkage models implemented are also discussed.

\section{MATERIALS AND METHODS}

\section{Study Population}

The current study used the National Institute of Mental Health (NIMH) Genetics Initiative AD Study sample. The AD family ascertainment was detailed elsewhere [Blacker et al., 1994, 2003]. The diagnosis of AD followed the NINCDS/ADRDA criteria [McKhann et al., 1984; Blacker et al., 1997]. The total sample is comprised of 437 independent families with at least two affected siblings, totaling 1,397 individuals. The families were classified as LOAD (320 families, $\mathrm{N}=973$ ) when all the affected individuals in a family had AAO $\geq 65$ years and early/ mixed (EOM) (117 families, $\mathrm{N}=424$ ) when at least one of the affected in a family had 50< AAO $<65$ years. For those affected, AAO is defined as the age at which family members or caregivers first noticed the cognitive impairment of the patients; for the unaffected, the AAE is defined as the age of the most recent screening exam at one of the study sites.

\section{Genotyping}

All the autosomes were genotyped by CIDR (Center for Inherited Disease Research) using 362 microsatellite markers (Marshfield 10 marker set) spaced at approximately every $9 \mathrm{cM}$. The genotyping techniques were detailed elsewhere [Blacker et al., 2003]. The APOE locus was genotyped using PCR and restriction enzyme digest [Blacker et al., 1997].

\section{Statistical Analysis}

The AAO for affected family members or AAE for unaffected family members was fit as the outcome in a parametric survival model [Amos et al., 2001; Yoo et al., 2001; Zeegers et al., 2004]. The logistic survival model was chosen for generality, as other standard models (e.g., Weibull and exponential) are special cases of this distribution. AAO for the affected is the time of the event whereas AAE for the unaffected is the time of the censoring. Main effects for gender and $\varepsilon 4$ allele dosage, modeled as two dummy variables for 1 or $2 \varepsilon 4$ alleles, were included as covariates. Gender by APOE $\varepsilon 4$ interactions were not significant in the survival analysis so they were left out of the model for the total sample and each subset for simplicity. Residuals were obtained for the total, LOAD, and EOM sets by the LIFEREG procedure in SAS v9 [SAS Institute]. In SAS, the log-logistic residual for the ith individual at time $t$ is defined as $\left[r_{j}=\mathrm{Obs}_{j}-\operatorname{Exp}_{j}\right]$ which estimates the difference between the observed time of events and the conditional expected time of events.

The survival analysis residuals were used as the quantitative trait in the variance-component linkage analysis in SOLAR version 2.1.4 [Almasy and Blangero, 1998]. To allow for possible familial covariance we included gender and $\varepsilon 4$ dosage (defined as above) as covariates in SOLAR. In addition, the analysis in SOLAR adjusted for all possible gender $\times \varepsilon 4$ interactions. Leaving all covariates out of the polygenic model in SOLAR yielded similar results, thus, we feel our analysis did not over adjust for $A P O E \varepsilon 4$ and gender. Significant covariates for a polygenic model were chosen by SOLAR, using the screening option (with default $P<0.10$ ) in fitting the polygenic model to form the null model for linkage analysis.

For comparison, $\mathrm{AAO}-\mathrm{AAE}$ was modeled as the quantitative trait in a subsequent linkage analysis. That is the quantitative trait data consisted of reported AAO for affected individuals and reported AAE for unaffected individuals. Affection status was used as a covariate in the 
model for adjustment of the contribution of reported AAO and AAE to the quantitative trait AAO. We included gender, $\varepsilon 4$ allele dosage (defined as above), affection status ( 1 for affected, 0 for unaffected), all possible two way interactions and three way gender $\times$ affection $\times \varepsilon 4$ interaction terms. As in the previous model the covariate screening option in the polygenic model in SOLAR was utilized. The AAO-AAE model was chosen for its similarity to the model implemented by Li et al. [2002].

\section{Linkage Analysis}

The multipoint variance-component procedure in SOLAR was used to test for the linkage between marker loci and the residual and AAO-AAE outcomes [Almasy and Blangero, 1998]. The variance components for the polygenic model are first calculated. This gives the total genetic variance and the residual variance from which the heritability is calculated. The polygenic model assumes a covariance structure defined by kinship coefficients, that is, the average amount of allele sharing identical by descent (IBD) across the entire autosomal genome, as defined by familial relationship. For each genetic locus examined, SOLAR then calculates the component of the total genetic variance defined by the estimated sharing IBD at that locus. The phenotype is assumed to follow a normal distribution. The test for linkage is performed by a likelihood-ratio test. Solar generates a LOD score that is equivalent to the classical LOD score of linkage analysis.

The methods for calculating IBD are identical to those implemented in the original genome scan of the NIMH AD Genetics Initiative dataset [Blacker et al., 2003] where the genetic maps and intermarker distances were provided by CIDR (www.cidr.jhmi.edu). Specifically, the multipoint estimate of allele sharing IBD between pairs of relatives within families was calculated in Genehunter [Kruglyak et al., 1996] assuming the Kosambi map function. The multipoint IBD information was imported into SOLAR for subsequent linkage analyses.

SOLAR calculates the residual kurtosis of the data following the polygenic model fit. For the AAO-AAE outcome, the kurtosis was within acceptable bounds, but the kurtosis was higher than the acceptable level for the residual outcome. To adjust the inflated level of evidence for linkage that would have resulted from the latter analysis, the t-distribution correction available in SOLAR was used.

\section{RESULTS}

Table I displays the characteristics of the total study population, LOAD and EOM subsets.

Table II displays heritability for the residual and AAO-AAE polygenic models in addition to $P$ values for parameter estimates of covariates calculated in SOLAR. Results show APOE $\varepsilon 4$ allele dosage contributes to variation in the trait for both the residual and AAO-AAE model even after adjustment for $A P O E \& 4$ at the survival model stage for the residual model. Interestingly, gender is significant only in the residual model for the total sample. Covariates not reaching statistical significance $(P<0.1)$ were selected out of the polygenic model for linkage analysis by SOLAR.

Table III shows the multipoint LOD scores $\geq 1$, nearest marker, and peak location for the residual and AAO-AAE linkage models for the total population and two AAO stratums (also shown for the total set in Fig. 1 across the autosomal genome). The strongest suggestive linkage regions are on chromosome 1 with a large peak in the total set with $\mathrm{LOD}=2.0$ for the residual model and $\mathrm{LOD}=1.4$ for the AAO-AAE model at $\sim 190 \mathrm{cM}$ and another large peak with LOD $=2.8$ and 1.3 for the AAO-AAE model and residual models respectively, among the LOAD sample at $137 \mathrm{cM}$ (Fig. 2).We also highlight peaks on 6p24, 6p21, 6q12, 6q20, 10p14, 10q21, 10q23, and 10q25 in Figure 2 since many regions on those chromosomes yield the largest peaks found by our study and are consistent with results from the original genome scan of the NIMH 
AD dataset and other AD linkage studies [Blacker et al., 2003]. Bolded peaks in Table III are within $30 \mathrm{cM}$ of a peak identified in the Blacker et al. [2003] study. Finally, there are additional peaks on 3q12, 3q13, 8q23, 9q34, 12q24, and 19q13 that meet criteria for suggestive linkage $(\mathrm{LOD} \geq 1.0)$ in the total sample and/or at least one onset-age stratum in at least one of the analyses.

\section{DISCUSSION}

We report the results of a high resolution genome scan for genes linked to $\mathrm{AAO}$ of $\mathrm{AD}$ in the large, uniformly ascertained and evaluated NIMH AD family set $(\mathrm{N}=1,397)$.

We observed linkage in two different outcome models including: (1) residuals from a parametric, logistic survival model for $\mathrm{AAO}$ of $\mathrm{AD}$ adjusted for gender and $\varepsilon 4$ allele dosage and (2) AAO of the affected and AAE of the unaffected family members. Variance-component linkage analysis was carried out in SOLAR adjusting for gender, $\varepsilon 4$ allele dosage, and affection status (AAO-AAE model only) including interactions, thus allowing for familial covariance. Overall results from the two linkage models are remarkably similar in the total population and each subset offering validation of study results (Fig. 1 and Fig. 2). This agrees with results from one study where authors compare power of three approaches to covariate adjustment in variance component linkage analysis, two of which are employed in our study, and conclude all three approaches seem to have similar power to detect a QTL and yield similar effect size estimates [Zeegers et al., 2004]. They suggest their results are only applicable to sib-pair data and further studies are needed to determine applicability to general pedigrees [Zeegers et al., 2004]. Since our cohort includes sib-pairs and multiplex families, our results suggest these methods may apply to more general pedigrees.

The heritability estimates for AD AAO for the total NIMH dataset and two subsets ranged from $33 \%$ to $74 \%$, which agree with twin studies that indicate heritability estimates for AAO range from 30\% to as high as 78\% [Gatz et al., 1997; Meyer and Breitner, 1998; Pedersen et al., 2001]. The linkage analysis by $\mathrm{Li}$ et al. [2002], where AD AAO was analyzed in a manner similar to the AAO-AAE model in our study, reported a heritability of $42 \%$. In comparison, heritability in the total set for the AAO-AAE model from our study was $73.6 \%$, however, the sample analyzed by $\mathrm{Li}$ et al. included families from other centers ( $40 \%$ of $\mathrm{Li}$ et al. sample) in addition to a subset of the NIMH sample [Li et al., 2002]. The differences in heritability estimates obtained for our study and the study by Li et al. are likely due to differences between the study populations. The full NIMH dataset used in the current study was not different by ascertainment, diagnostic criteria or proportion of families contributed from each site than the subset used in the study by Li et al. Interestingly, the affected to unaffected family member ratio in the Li et al. study was smaller than for our study indicating possible ascertainment differences between the NIMH families and non-NIMH families included in that study. We considered that since the AAO of the non-NIMH families in the Li et al. study are not reported separately, it is possible that they are disproportionately represented by EOM families, and therefore would have lower heritability, since heritability for the EOM families in the NIMH sample was estimated to be $33 \%$.

Studies have concluded that adjusting for covariates can strengthen the power to detect QTLs for complex diseases [Hauser et al., 2003; Schaid et al., 2003; Zeegers et al., 2004]. Therefore, we included host and environmental factors shown to be associated with AAO in AD, including gender, and $\varepsilon 4$ allele dosage [Blacker et al., 1997; Khachaturian et al., 2004; Kim et al., 2005]. As expected many covariates and their interactions were significant in both models (Table II). Higher education is known to be associated with older AAO of AD and was reported for the majority of the NIMH sample (83\%) [Kim et al., 2005]. However, we are concerned that education is not missing at random and, therefore, did not include that variable in our 
analyses as it would be difficult to determine if differences in results are due to covariate adjustment or differences in the sample due to exclusion of those with missing education. In addition to adjusting for covariates we stratified by AAO of the affected individual(s) at the family level (EOM and LOAD). Figure 2 highlights how AAO stratum can refine peak regions such as on chromosome 6 between 70 and $85 \mathrm{cM}$ and chromosome 10 around $120 \mathrm{cM}$ where the peaks for the LOAD group are greater in magnitude than for the total and EOM sets. This suggests that by analyzing larger study populations chromosomal regions important for AD AAO in different AAO stratums may be yet uncovered.

Other studies have identified the $A P O E$ gene as a significant modifying factor for AAO of AD [Corder et al., 1993; Blacker et al., 1997; Khachaturian et al., 2004]. The study from which we obtained methods for our AAO-AAE model reported LOD $=3.28$ in the region of APOE [Li et al., 2002]. In the original scan for AD risk of this same NIMH population, there is a highly significant peak in the EOM stratum on chromosome 19q13 (LOD = 7.7) at marker D19S178, which maps within $1 \mathrm{Mb}$ of APOE. Linkage evidence for LOAD families in the 2003 scan of the NIMH dataset was less pronounced, and peaked $17 \mathrm{cM}$ proximal (LOD = 1.6) at marker D19S433 [Blacker et al., 2003]. Two recent genome wide association (GWA) studies have highlighted markers linked to $A P O E$ as significantly associated with LOAD after corrections for multiple testing [Coon et al., 2007; Grupe et al., 2007]. As the influence of APOE on AD is well established, our study sought to adjust for $\varepsilon 4$ allele dosage to allow identification of other peaks on chromosome 19 , however no other significant peaks on chromosome 19 were identified. The peaks in the region of $A P O E$ for the AAO-AAE model may be due to residual variation as the residual outcome model had LOD $<0.4$ in that region for the total and LOAD groups. For possibly identifying additional modifying effects of $A P O E$, we completed the autosomal genome scan without $\varepsilon 4$ allele adjustment and found that $A P O E$ had no effect on peak positions and minor effects on peak size (data not shown). When we included the $A P O E$ locus in the total NIMH dataset and each subset as a marker and removed it as a covariate, peaks in the region of $A P O E$ almost doubled in size though not with LOD > 1.0 for the residual model or LOD > 2.0 for the AAO-AAE model. Consistent with the linkage scan for risk of $\mathrm{AD}$ in the same population [Blacker et al., 2003], our results suggest that $A P O E$ has very moderate effects on LOAD AAO.

Our results show peaks with $\mathrm{LOD} \geq 1.0$ on chromosome 1 in the total and LOAD groups at 49, 137, and $190 \mathrm{cM}$ for both outcome models. Interestingly, in the study of risk for AD in the same NIMH dataset [Blacker et al., 2003] a peak at $27 \mathrm{cM}(\mathrm{LOD}=1.1)$ in the LOAD subset was reported while the current study found a comparable peak at $49 \mathrm{cM}$ in the LOAD subset. Other comparable peaks were located at $178 \mathrm{cM}(\mathrm{LOD}=1.1)$ in the LOAD group in the original scan and $190 \mathrm{cM}$ in the total set in the current study (LOD =2.0), almost double the LOD score reported by the original study. The original study also reports a peak with LOD $=1.6$ in the EOM set at $121 \mathrm{cM}$ where we report a peak at $137 \mathrm{cM}$ for the AAO-AAE model with LOD = 2.8 in the LOAD set, again, almost double that of the original genome scan in a comparable region on chromosome 1 , though in a different AAO stratum. We feel the increase in magnitude of peaks around 130 and $190 \mathrm{cM}$ on chromosome 1 in our study compared to the original genome scan for AD risk could suggest genes associated with AD AAO other than AD risk lie in those regions. Linkage analysis of the EOM group in our study resulted in a peak (LOD = $1.0)$ at $219 \mathrm{cM}$ on chromosome 1 which is consistent with another study where there was evidence for a QTL for AAO near the presenilin 2 (PS2) gene $(\sim 240 \mathrm{cM})$ (among a set of families known to carry a point mutation in PS2) [Daw et al., 1999].

Our study also highlighted a peak on chromosome 3 at $116 \mathrm{cM}$ with LOD $=1.7$ in the EOM set for the residual model and LOD $=1.3$ for the AAO-AAE model, however we note the analysis of this subgroup may be prone to type I error as sample size is small. The original scan resulted in a more proximal peak at $88 \mathrm{cM}$ in the total set with a smaller $\mathrm{LOD}=1.1$. This region 
of chromosome 3 was not highlighted in two other linkage studies examining AAO of AD [ $\mathrm{Li}$ et al., 2002; Holmans et al., 2005].

Evidence for linkage to chromosome 6 has been demonstrated by other studies [Li et al., 2002; Blacker et al., 2003; Holmans et al., 2005]. The original genome scan for AD risk of the NIMH dataset reported a peak in the total set at $64 \mathrm{cM}$ on chromosome 6 with MLS $=1.0$ and TLS $=1.9$ [Blacker et al., 2003] close to peaks in the LOAD and total sets found by this analysis of the same population. Our study did not show a linkage signal on 6q27 that the original study reported $(\mathrm{LOD}=2.2$ at $181 \mathrm{cM})$. Our peaks on chromosome 6 between 69 and $86 \mathrm{cM}$ in the total and LOAD subset are consistent with the peak found on chromosome 6 in an affected sibpair linkage analysis of a subset ( $\mathrm{N}=277$ sibpairs) of the NIMH sample [Holmans et al., 2005]. Specifically, after adjustment for AAO difference and APOE, a peak at $74 \mathrm{cM}$ with $\mathrm{LOD}=2.4$ was found in that study suggesting a gene affecting AAO could lie within that region [Holmans et al., 2005]. Using variance-component methods in SOLAR similar to our AAO-AAE outcome model, $\mathrm{Li}$ et al. [2002] found a peak $(\mathrm{LOD}=1.17)$ at $51 \mathrm{cM}$ on chromosome 6 close to where peaks were identified in the total set and LOAD subset in our study. Additionally, they reported a peak on chromosome $8(\mathrm{LOD}=2.09)$ at $150 \mathrm{cM}$ within $25 \mathrm{cM}$ of a peak identified in our study in the EOM subset.

Risk and AAO studies have reported linkage peaks for AD on chromosome 10 [Bertram et al., 2000; Li et al., 2002; Myers et al., 2002; Blacker et al., 2003; Holmans et al., 2005]. Results for chromosome 10 reveal many similarities between the original linkage scan for AD risk and our study. A peak at $19 \mathrm{cM}$ in the original scan in the EOM group is consistent with a peak at $29 \mathrm{cM}$ in that same sub-group in the current study. Additionally, both studies report peaks between 80 and $135 \mathrm{cM}$. In fact, the original scan of the NIMH dataset concludes chromosome 10 may harbor unique $\mathrm{AD}$ susceptibility genes due to consistency with previous linkage reports on AD risk [Blacker et al., 2003].

Our study reveals a peak with $\mathrm{LOD}=1.8$ on chromosome 10 for the AAO-AAE outcome and 1.0 for the residual outcome at marker D10S1225 $(81 \mathrm{cM})$ in the LOAD sub-group that is consistent with suggestive linkage regions in independent AD risk gene studies [Myers et al., 2002; Blacker et al., 2003; Ertekin-Taner et al., 2003; Holmans et al., 2005]. Though their methods are different than ours, the affected sib-pair linkage analysis by Holmans et al. [2005], suggests this region is more important for AD risk than AD AAO as adjustment for AAO difference or AAO mean did not alter the linkage signal $(\mathrm{LOD}=4.0)$ at marker D10S1225. Interestingly, using plasma amyloid $\beta$ protein (A $\beta 42)$ levels as a quantitative intermediate phenotype for LOAD, another study found a significant linkage peak near our peak at $80 \mathrm{cM}$ on chromosome 10 [Ertekin-Taner et al., 2000]. The authors identified a candidate gene (VR22) located at $80 \mathrm{cM}$ that encodes $\alpha$-T catenin [Janssens et al., 2001; ErtekinTaner et al., 2003]. A recent study sequenced VR22 in multiplex families, identified a novel non-synonymous (Ser596Asn; rs4548513) SNP, and tested association of that SNP and four other non-coding SNPs with AD in two independent study samples. They reported a weak association with the Ser596Asn SNP, predominantly in families with LOAD $(P=0.02)$, but concluded this association does not seem to contribute substantially to the chromosome $10 \mathrm{AD}$ linkage signal and suggest further research is needed [Bertram et al., 2007].

Though it is difficult to distinguish regions important for $\mathrm{AD}$ risk from regions important for AD AAO on chromosome 10, the most suggestive linkage region for AD AAO on chromosome 10 may lie in the region of D10S1237 and D10S677. The linkage study by Li et al. [2002] using both NIMH and non-NIMH families reports a peak associated with AD AAO at marker D10S1237 ( $\mathrm{LOD}=2.39,134 \mathrm{cM}$ ) within $2 \mathrm{cM}$ of a peak (LOD = 1.1) from our residual model and within $15 \mathrm{cM}$ from peaks resulting from the residual and AAO-AAE models in the LOAD subset in our study $(\mathrm{LOD}=1.4$ and 1.2, respectively at marker D10S677 at $119 \mathrm{cM})$. In a 
follow-up linkage analysis, Li's group concluded that a glutathione S-transferase omega (GSTO1-GSTO2) haplotype drives the original linkage signal at D10S1237 (134 cM) making these genes of interest for their modifying effect on AD AAO [Li et al., 2006]. Li et al. also reports a linkage peak for AD AAO with LOD $=1.0$ at D10S677 $(119 \mathrm{cM})$ when analyzing a subset of the NIMH AD dataset alone, noted here because we found consistent results with the full NIMH AD dataset using similar methods at that marker. Interestingly, a recent association study reported one SNP, rs498055, that maps within $12 \mathrm{cM}$ of D10S677 located in a gene homologous to RPS3A was significantly associated with LOAD in four of six case-control series and reported association $P=0.0001$ for a meta analysis of all six samples [Grupe et al., 2006].

There have been several reports of genetic linkage for risk of $\mathrm{AD}$ to chromosome 12, many from studies of LOAD samples with linkage peaks spanning between $\sim 6 \mathrm{cM}$ and $\sim 70 \mathrm{cM}$ [Pericak-Vance et al., 1997; Rogaeva et al., 1998; Wu et al., 1998; Scott et al., 1999; Poduslo and Yin, 2001; Mayeux et al., 2002; Myers et al., 2002]. In contrast, neither our study nor the original 2003 scan, found evidence of linkage to the $12 p$ region. In the current analysis there is a suggestive peak on chromosome $12 \mathrm{q}(\mathrm{LOD}=1.7, \sim 170 \mathrm{cM})$ that was present in the EOM subset only, though this set is small $(\mathrm{N}=117$ families) and may be more prone to type I error.

Our models did result in peaks with LOD > 1.0 in some of the same regions of chromosomes $1,3,6$, and 10 that were highlighted by the original genome scan for AD risk [Blacker et al., 2003]. Interestingly, a recent GWA study of LOAD [Grupe et al., 2007] highlighted markers on chromosome 1 (at about $148 \mathrm{cM}$ ) and $10($ at $131 \mathrm{cM}$ ) within $10 \mathrm{cM}$ of peaks highlighted by the linkage studies of AD risk and AAO in the LOAD group of the NIMH dataset. There were several noteworthy peaks (LOD > 2.0) highlighted in the original scan of AD risk that our study of AAO did not pick up like the peak on $14 \mathrm{q}$ at $55 \mathrm{cM}(\mathrm{MLS}=2.9)$ in the EOM subset. However, it is noteworthy that the peaks in our study are sharper (Fig. 2) than the peaks of the original study because our study uses more information by including unaffected family members where the original study is an affected only analysis [Blacker et al., 2003].

Additionally, peaks on chromosomes 1, 6, and 10 found in our study were stronger when we included unaffected family members versus an affected-only linkage analysis for AD AAO (data not shown). This supports the theory that including unaffected family members in QTL linkage analysis can increase power to detect regions associated with the trait [Wijsman and Amos, 1997; Almasy and Blangero, 1998].

In conclusion, employing two different methods for covariate adjusted quantitative trait linkage analysis for $\mathrm{AAO}$ in $\mathrm{AD}$ we found that regions on chromosomes 1, 6, and 10 harbor the most influential loci on AAO after adjustment (Fig. 2). Additional suggestive peak regions on chromosomes 2, 3, 8, 9, 12, and 19 were also identified. We provide additional evidence that genes associated with AD AAO may be located on chromosome 1, since peaks in the region of 130 and $190 \mathrm{cM}$ almost doubled in our study of AD AAO compared to the original linkage scan of the NIMH population for AD risk [Blacker et al., 2003]. However, these results should be considered suggestive and therefore require further investigation since peaks on chromosome 1 never reach LOD > 3.0 for either study. For other autosomes it is difficult to distinguish regions of the genome important for $\mathrm{AD}$ risk from regions important for $\mathrm{AD} \mathrm{AAO}$ since the magnitude of peaks found in common between our study and the original genome scan [Blacker et al., 2003] are not notably different, especially for our primary linkage model utilizing the residual statistics approach. However, the consistency of results in our two linkage models and with other linkage studies focused on AD AAO suggest genomic regions that may harbor AAO moderating genes warrant follow-up in the future. 


\section{ACKNOWLEDGMENTS}

Data and biomaterials were collected in three projects that participated in the National Institute of Mental Health (NIMH) Alzheimer Disease Genetic Initiative. From 1991 to 1998, the Principal Investigators and Co-Investigators were located at Massachusetts General Hospital, Boston, MA, U01 MH46281; Johns Hopkins University, Baltimore, MD, U01 MH46290; and University of Alabama at Birmingham, Birmingham, AL, U01 MH46373. We are thankful for the dedicated and caring families participating in the NIMH study.

\section{REFERENCES}

Abecasis GR, Cherny SS, Cookson WO, Cardon LR. Merlin-rapid analysis of dense genetic maps using sparse gene flow trees. Nat Genet 2002;30(1):97-101. [PubMed: 11731797]

Almasy L, Blangero J. Multipoint quantitative-trait linkage analysis in general pedigrees. Am J Hum Genet 1998;62:1198-1211. [PubMed: 9545414]

Amos CI, Shete S, Gu X. Variance components analysis for genetic linkage of time to onset for disease. Genet Epidemiol 2001;21:S768-S773. [PubMed: 11793775]

Bertram L, Tanzi RE. The current status of Alzheimer's disease genetics: What do we tell the patients? Pharmacol Res 2004;50(4):385-396. [PubMed: 15304236]

Bertram L, Blacker D, Mullin K, Keeney D, Jones J, Basu S, Yhu S, McInnis MG, Go RC, Vekrellis K, et al. Evidence for genetic linkage of Alzheimer's disease to chromosome 10q. Science 2000;290 (5500):2302-2303. [PubMed: 11125142]

Bertram L, Mullin K, Parkinson M, Hsiao M, Moscarillo TJ, Wagner SL, Becker KD, Velicelebi G, Blacker D, Tanzi RE. Is alpha-T catenin (VR22) an Alzheimer's disease risk gene? J Med Genet 2007;44(1):e63. [PubMed: 17209133]

Beyer K, Lao JI, Latorre P, Ariza A. Age at onset: An essential variable for the definition of genetic risk factors for sporadic Alzheimer's disease. Ann N Y Acad Sci 2005;1057:260-278. [PubMed: 16399900]

Bickeboller H, Campion D, Brice A, Amouyel P, Hannequin D, Didierjean O, Penet C, Martin C, PerezTur J, Michon A, et al. Apolipoprotein E and Alzheimer disease: Genotype-specific risks by age and sex. Am J Hum Genet 1997;60(2):439-446. [PubMed: 9012418]

Blacker D, Albert MS, Bassett SS, Go RC, Harrell LE, Folstein MF. The National Institute of Mental Health Genetics Initiative. Reliability and validity of NINCDS-ADRDA criteria for Alzheimer's disease. Arch Neurol 1994;51(12):1198-1204. [PubMed: 7986174]

Blacker D, Haines JL, Rodes L, Terwedow H, Go RC, Harrell LE, Perry RT, Bassett SS, Chase G, Meyers D, et al. ApoE-4 and age at onset of Alzheimer's disease: The NIMH genetics initiative. Neurology 1997;48(1):139-147. [PubMed: 9008509]

Blacker D, Bertram L, Saunders AJ, Moscarillo TJ, Albert MS, Wiener H, Perry RT, Collins JS, Harrell LE, Go RC, et al. Results of a high-resolution genome screen of 437 Alzheimer's disease families. Hum Mol Genet 2003;12(1):23-32. [PubMed: 12490529]

Coon KD, Myers AJ, Craig DW, Webster JA, Pearson JV, Lince DH, Zismann VL, Beach TG, Leung $\mathrm{D}$, Bryden L, et al. A high-density whole-genome association study reveals that APOE is the major susceptibility gene for sporadic late-onset Alzheimer's disease. J Clin Psychiatry 2007;8(4):613618. [PubMed: 17474819]

Corder EH, Saunders AM, Strittmatter WJ, Schmechel DE, Gaskell PC, Small GW, Roses AD, Haines JL, Pericak-Vance MA. Gene dose of apolipoprotein E type 4 allele and the risk of Alzheimer's disease in late onset families. Science 1993;261(5123):921-923. [PubMed: 8346443]

Daw EW, Heath SC, Wijsman EM. Multipoint oligogenic analysis of age-at-onset data with applications to Alzheimer disease pedigrees. Am J Hum Genet 1999;64(3):839-851. [PubMed: 10053019]

Daw EW, Payami H, Nemens EJ, Nochlin D, Bird TD, Schellenberg GD, Wijsman EM. The number of trait loci in late-onset Alzheimer disease. Am J Hum Genet 2000;66(1):196-204. [PubMed: 10631151]

Ertekin-Taner N, Graff-Radford N, Younkin LH, Eckman C, Baker M, Adamson J, Ronald J, Blangero J, Hutton M, Younkin SG. Linkage of plasma Abeta42 to a quantitative locus on chromosome 10 in late-onset Alzheimer's disease pedigrees. Science 2000;290(5500):2303-2304. [PubMed: 11125143] 
Ertekin-Taner N, Ronald J, Asahara H, Younkin L, Hella M, Jain S, Gnida E, Younkin S, Fadale D, Ohyagi $\mathrm{Y}$, et al. Finemapping of the alpha-T catenin gene to a quantitative trait locus on chromosome 10 in late-onset Alzheimer's disease pedigrees. Hum Mol Genet 2003;12(23):3133-3143. [PubMed: 14559775]

Farrer LA, Cupples LA, Haines JL, Hyman B, Kukull WA, Mayeux R, Myers RH, Pericak-Vance MA, Risch N, van Duijn CM. Effects of age, sex, and ethnicity on the association between apolipoprotein E genotype and Alzheimer disease. A meta-analysis. APOE and Alzheimer Disease Meta Analysis Consortium. JAMA 1997;278(16):1349-1356. [PubMed: 9343467]

Gatz M, Pedersen NL, Berg S, Johansson B, Johansson K, Mortimer JA, Posner SF, Viitanen M, Winblad B, Ahlbom A. Heritability for Alzheimer's disease: The study of dementia in Swedish twins. J Gerontol A Biol Sci Med Sci 1997;52:M117-M125. [PubMed: 9060980]

Grupe A, Li Y, Rowland C, Nowotny P, Hinrichs AL, Smemo S, Kauwe JS, Maxwell TJ, Cherny S, Doil L, et al. A scan of chromosome 10 identifies a novel locus showing strong association with late-onset Alzheimer disease. Am J Hum Genet 2006;78(1):78-88. [PubMed: 16385451]

Grupe A, Abraham R, Li Y, Rowland C, Hollingworth P, Morgan A, Jehu L, Segurado R, Stone D, Schadt E, et al. Evidence for novel susceptibility genes for late-onset Alzheimer's disease from a genomewide association study of putative functional variants. Hum Mol Genet 2007;16(8):865-873. [PubMed: 17317784]

Hagnell O, Ojesjo L, Rorsman B. Incidence of dementia in the Lund by Study. Neuroepidemiology 1992;11:61-66. [PubMed: 1603251]

Hauser ER, Hsu FC, Daley D, Olson JM, Rampersaud E, Lin JP, Paterson AD, Poisson LM, Chase GA, Dahmen G, et al. Effects of covariates: A summary of Group 5 contributions. Genet Epidemiol 2003;25:S43-S49. [PubMed: 14635168]

Holmans P, Hamshere M, Hollingworth P, Rice F, Tunstall N, Jones S, Moore P, Wavrant DeVrieze F, Myers A, Crook R, et al. Genome screen for loci influencing age at onset and rate of decline in late onset Alzheimer's disease. Am J Med Genet Part B 2005;135B(1):24-32.

Janssens B, Goossens S, Staes K, Gilbert B, van Hengel J, Colpaert C, Bruyneel E, Maree M, van Roy F. Alpha T-catenin: A novel tissue-specific beta-catenin-binding protein mediating strong cell-cell adhesion. J Cell Sci 2001;114(Pt 17):3177-3188. [PubMed: 11590244]

Khachaturian AS, Corcoran CD, Mayer LS, Zandi PP, Breitner JC. Apolipoprotein E epsilon4 count affects age at onset of Alzheimer disease, but not lifetime susceptibility: The Cache County Study. Arch Gen Psychiatry 2004;61(5):518-524. [PubMed: 15123497]

Kim KY, Wood BE, Wilson MI. Risk factors for Alzheimer's disease: An overview for clinical practitioners. Consult Pharm 2005;20(3):224-230. [PubMed: 16548629]

Kruglyak L, Daly MJ, Reeve-Daly MP, Lander ES. Parametric and nonparametric linkage analysis: A unified multipoint approach. Am J Hum Genet 1996;58(6):1347-1363. [PubMed: 8651312]

Li H. An additive genetic gamma frailty model for linkage analysis of diseases with variable age of onset using nuclear families. Lifetime Data Anal 2002;8(4):315-334. [PubMed: 12471942]

Li YJ, Scott WK, Hedges DJ, Zhang F, Gaskell PC, Nance MA, Watts RL, Hubble JP, Koller WC, Pahwa $\mathrm{R}$, et al. Age at onset in two common neurodegenerative diseases is genetically controlled. Am $\mathrm{J}$ Hum Genet 2002;70(4):985-993. [PubMed: 11875758]

Li YJ, Scott WK, Zhang L, Lin PI, Oliveira SA, Skelly T, Doraiswamy MP, Welsh-Bohmer KA, Martin ER, Haines JL, et al. Revealing the role of glutathione S-transferase omega in age-at-onset of Alzheimer and Parkinson diseases. Neurobiol Aging 2006;27(8):1087-1093. [PubMed: 15985314]

Mayeux R, Lee JH, Romas SN, Mayo D, Santana V, Williamson J, Ciappa A, Rondon HZ, Estevez P, Lantigua R, et al. Chromosome-mapping of late-onset Alzheimer disease among Caribbean Hispanics. Am J Hum Genet 2002;70(1):237-243. [PubMed: 11715112]

McKhann G, Drachman D, Folstein M, Katzman R, Price D, Stadlan EM. Clinical diagnosis of Alzheimer's disease: Report of the NINCDS-ADRDA Work Group under the auspices of Department of Health and Human Services Task Force on Alzheimer's Disease. Neurology 1984;34(7):939-944. [PubMed: 6610841]

Meyer JM, Breitner JC. Multiple threshold model for the onset of Alzheimer's disease in the NAS-NRC twin panel. Am J Med Genet 1998;81(1):92-97. [PubMed: 9514594] 
Miech RA, Breitner JC, Zandi PP, Khachaturian AS, Anthony JC, Mayer L. Incidence of AD may decline in the early 90s for men, later for women: The Cache County study. Neurology 2002;58(2):209-218. [PubMed: 11805246]

Myers A, WavrantDe-Vrieze F, Holmans P, Hamshere M, Crook R, Compton D, Marshall H, Meyer D, Shears S, Booth J, et al. Full genome screen for Alzheimer disease: Stage II analysis. Am J Med Genet 2002;114(2):235-244. [PubMed: 11857588]

Pankratz VS, de Andrade M, Therneau TM. Random-effects Cox proportional hazards model: General variance components methods for time-to-event data. Genet Epidemiol 2005;28(2):97-109. [PubMed: 15532036]

Pedersen NL, Posner SF, Gatz M. Multiple-threshold models for genetic influences on age of onset for Alzheimer disease: Findings in Swedish twins. Am J Med Genet 2001;105(8):724-728. [PubMed: 11803520]

Pericak-Vance MA, Bass MP, Yamaoka LH, Gaskell PC, Scott WK, Terwedow HA, Menold MM, Conneally PM, Small GW, Vance JM, et al. Complete genomic screen in late-onset familial Alzheimer disease. Evidence for a new locus on chromosome 12. JAMA 1997;278(15):1237-1241. [PubMed: 9333264]

Poduslo SE, Yin X. Chromosome 12 and late-onset Alzheimer's disease. Neurosci Lett 2001;310(2-3): 188-190. [PubMed: 11585598]

Rocchi A, Pellegrini S, Siciliano G, Murri L. Causative and susceptibility genes for Alzheimer's disease: A review. Brain Res Bull 2003;61(1):1-24. [PubMed: 12788204]

Rogaeva E, Premkumar S, Song Y, Sorbi S, Brindle N, Paterson A, Duara R, Levesque G, Yu G, Nishimura M, et al. Evidence for an Alzheimer disease susceptibility locus on chromosome 12 and for further locus heterogeneity. JAMA 1998;280(7):614-618. [PubMed: 9718052]

Schaid DJ, Olson JM, Gauderman WJ, Elston RC. Regression models for linkage: Issues of traits, covariates, heterogeneity, and interaction. Hum Hered 2003;55(2-3):86-96. [PubMed: 12931047]

Scott WK, Grubber JM, Abou-Donia SM, Church TD, Saunders AM, Roses AD, Pericak-Vance MA, Conneally PM, Small GW, Haines JL. Further evidence linking late-onset Alzheimer disease with chromosome 12. JAMA 1999;281(6):513-514. [PubMed: 10022104]

Scurrah KJ, Palmer LJ, Burton PR. Variance components analysis for pedigree-based censored survival data using generalized linear mixed models (GLMMs) and Gibbs sampling in BUGS. Genet Epidemiol 2000;19(2):127-148. [PubMed: 10962474]

Tanzi RE. A genetic dichotomy model for the inheritance of Alzheimer's disease and common age-related disorders. J Clin Invest 1999;104(9):1175-1179. [PubMed: 10545516]

Wijsman EM, Amos CI. Genetic analysis of simulated oligogenic traits in nuclear and extended pedigrees: Summary of GAW10 contributions. Genet Epidemiol 1997;14:719-735. [PubMed: 9433569]

Wu WS, Holmans P, Wavrant-DeVrieze F, Shears S, Kehoe P, Crook R, Booth J, Williams N, Perez-Tur J, Roehl K, et al. Genetic studies on chromosome 12 in late-onset Alzheimer disease. JAMA 1998;280 (7):619-622. [PubMed: 9718053]

Yoo B, Pankratz VS, de Andrade M. Practical application of residuals from survival models in quantitative trait linkage analysis. Genet Epidemiol 2001;21(Suppl 1):S811-S816. [PubMed: 11793784]

Zeegers M, Rijsdijk F, Sham P. Adjusting for covariates in variance components QTL linkage analysis. Behav Genet 2004;34(2):127-133. [PubMed: 14755177] 
Total NIMH Sample

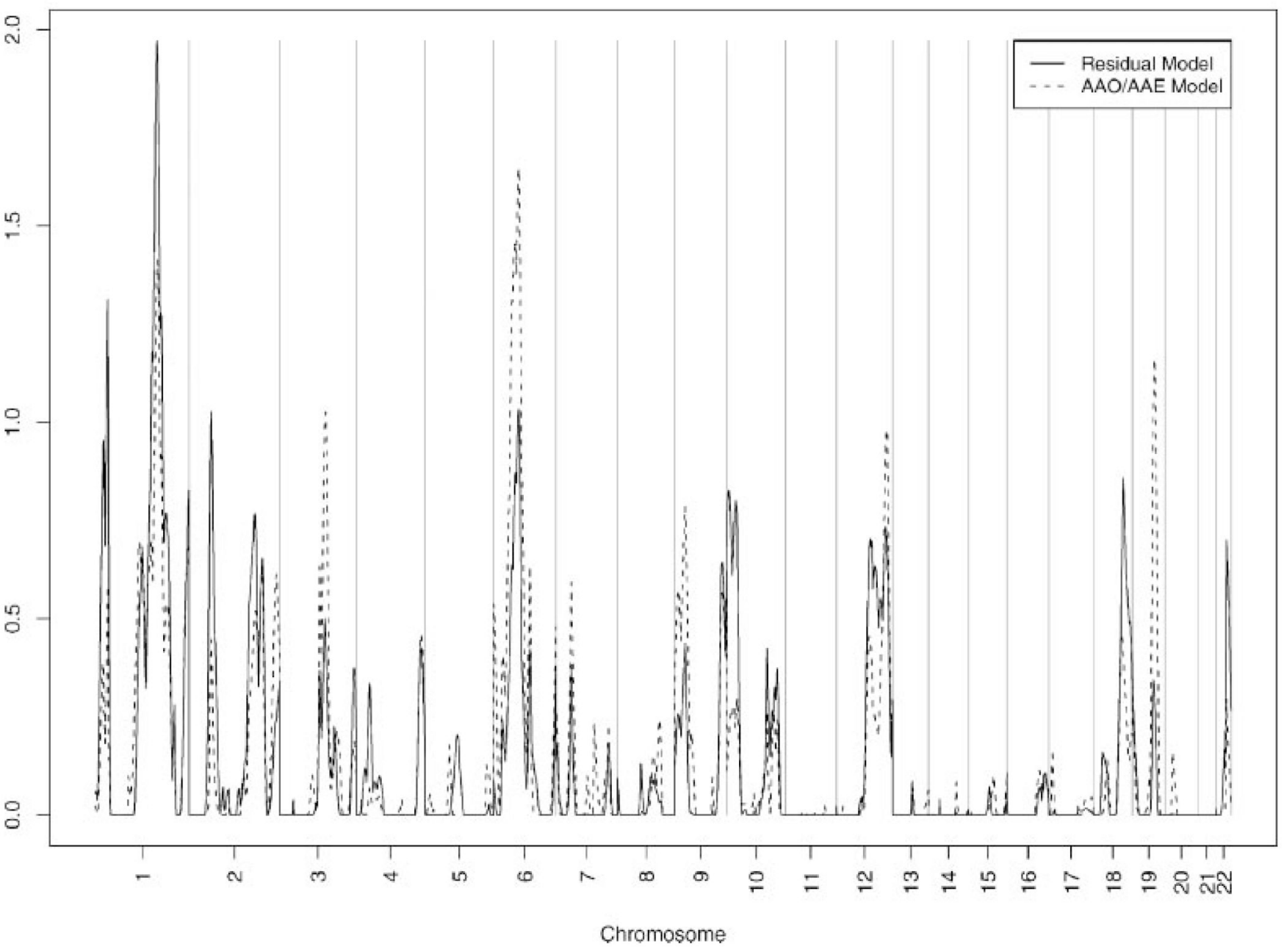

Fig. 1.

Linkage results for Residual and AAO/AAE models in variance-component linkage analysis for each autosome in the Total NIMH Genetic Initiative AD Sample of 437 Families. 

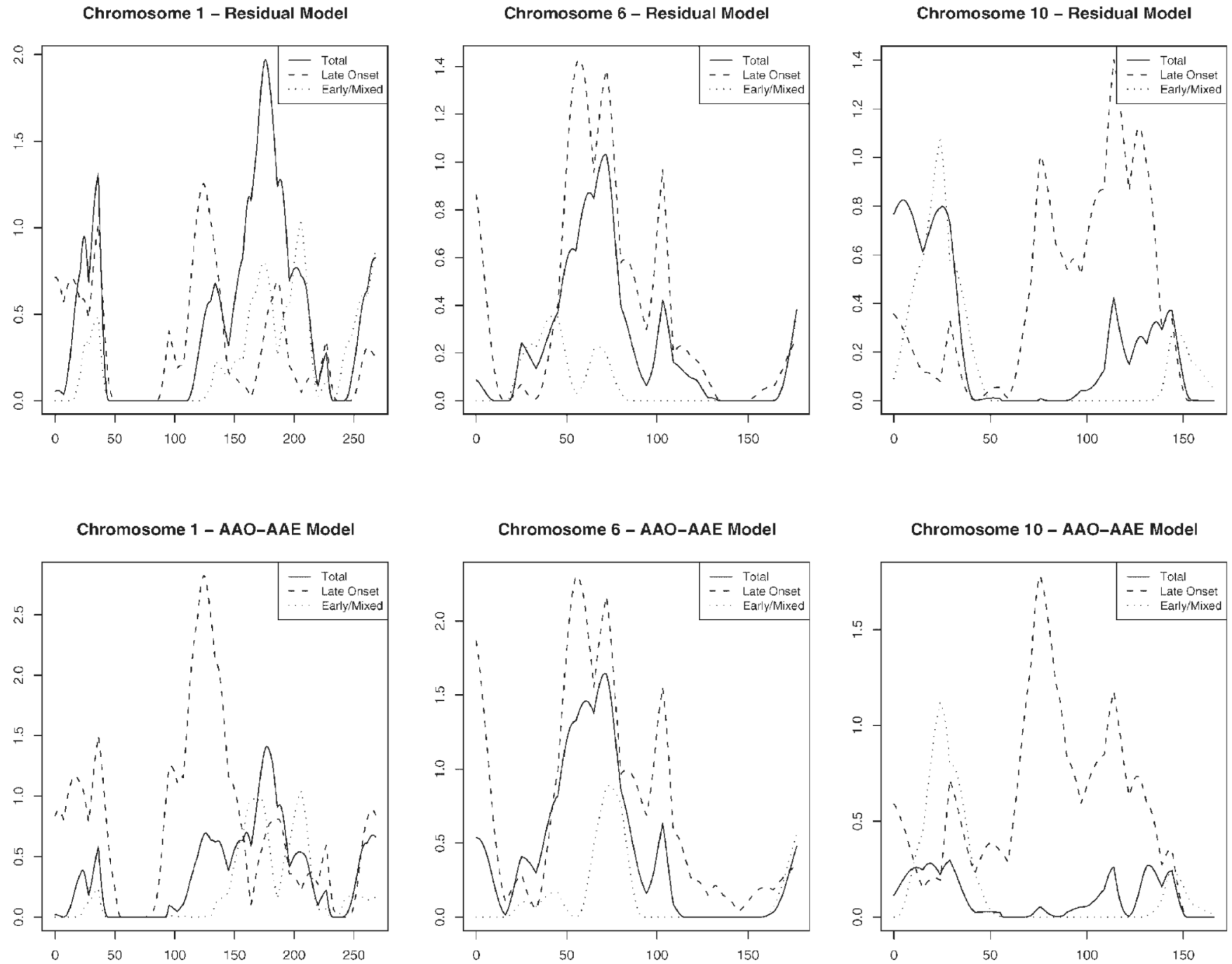

Fig. 2.

Linkage results for Residual and AAO/AAE models in variance-component linkage analysis for chromosomes 1,6 , and 10 . 
Table I

The Descriptive Statistics of the Outcomes and Covariates in the Total, Late-Onset, and Early/Mixed Sets of the NIMH Genetic Initiative AD Sample of 437 Families

\begin{tabular}{lccc}
\hline Variable & Total group & Late-onset & Early/mixed \\
\hline Number affected & 990 & 717 & 273 \\
Age at onset (SD) & $72.37(7.71)$ & $74.91(6.03)$ & $65.78(7.77)$ \\
Number unaffected & 407 & 256 & 151 \\
Age at exam (SD) & $69.80(11.05)$ & $71.42(10.41)$ & $66.99(11.61)$ \\
Number male (\%) & $432(31)$ & $277(28)$ & $155(37)$ \\
No APOE4 alleles (\%) & $468(34)$ & $357(37)$ & $111(26)$ \\
One APOE4 allele (\%) & $717(51)$ & $520(53)$ & $197(46)$ \\
Two APOE4 alleles & $212(15)$ & $96(10)$ & $116(28)$ \\
\hline
\end{tabular}




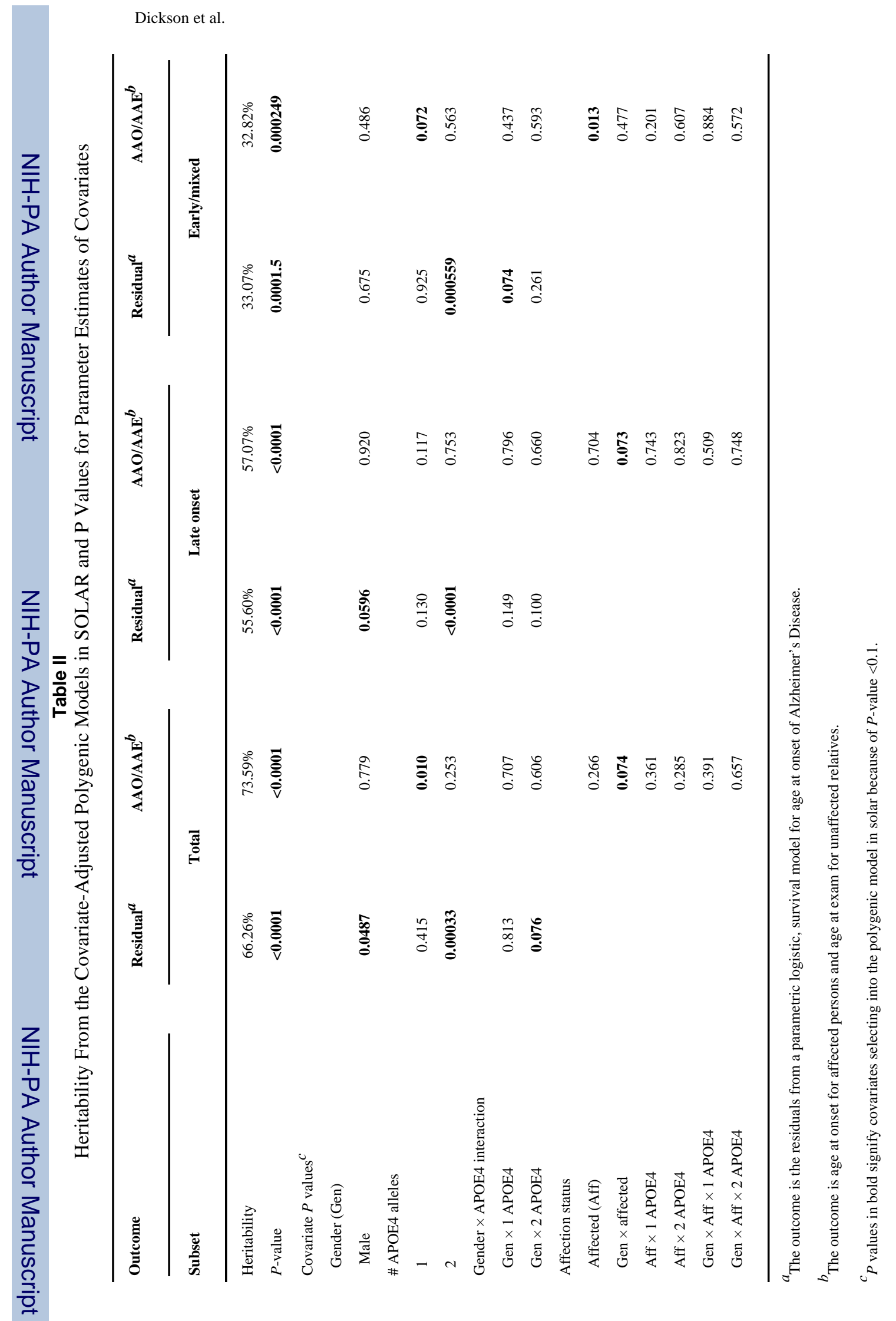

Page 15 
Table III

Peak Regions With Multipoint LOD $\geq 1$ for Variance Components Linkage Analysis of Age at Onset of Alzheimer's Disease in the NIMH Genetic Initiative AD Sample ( $=437$ Families)

\begin{tabular}{|c|c|c|c|c|}
\hline Chromosome:Marker (cM) ${ }^{a}$ & Stratum & Model $^{b, c}$ & $\mathbf{c M}$ & $\operatorname{MLS}^{d}$ \\
\hline 1:D1S552 (49) & Total & Residual only & 49 & 1.3 \\
\hline 1:D1S552 (49) & Late & Residual/AAO-AAE & 49 & $1.0 / 1.5$ \\
\hline 1:D1S1588 (132) & Late & Residual/AAO-AAE & 137 & $1.3 / 2.8$ \\
\hline 1:D1S1619 (195) & Total & Residual/AAO-AAE & $190 / 191$ & 2.0/1.4 \\
\hline 1:D1S1660 (219) & Early and mixed & Residual/AAO-AAE & 219 & $1.0 / 1.0$ \\
\hline 2:D2S1356 (66) & Total & Residual only & 66 & 1.0 \\
\hline 2:D2S1356 (66) & Early and mixed & Residual only & 68 & 1.2 \\
\hline 2:D2S2968 (252) & Early and mixed & Residual/AAO-AAE & 252 & $1.1 / 1.0$ \\
\hline 3:D3S2459 (116) & Early and mixed & Residual/AAO-AAE & $116 / 117$ & $1.7 / 1.3$ \\
\hline 3:D3S4523 (134) & Total & AAO-AAE only & 133 & 1.0 \\
\hline 6:F13A1 (14) & Late & AAO-AAE only & 14 & 1.9 \\
\hline 6:D6S1017 (69) & Late & Residual/AAO-AAE & $71 / 69$ & $1.4 / 2.3$ \\
\hline 6:D6S1053 (86) & Total & Residual/AAO-AAE & 85 & $1.0 / 1.6$ \\
\hline 6:D6S1053 (86) & Late & Residual/AAO-AAE & 86 & $1.4 / 2.2$ \\
\hline 6:D6S1021 (117) & Late & Residual/AAO-AAE & 117 & $1.0 / 1.6$ \\
\hline 8:D8S1132 (124) & Early and mixed & Residual only & 124 & 1.1 \\
\hline 9:D9S1826 (165) & Early and mixed & AAO-AAE only & 158 & 1.1 \\
\hline 10:D10S1412 (29) & Early and mixed & Residual/AAO-AAE & 29 & 1.1/1.1 \\
\hline 10:D10S1225 (81) & Late & Residual/AAO-AAE & 81 & $1.0 / 1.8$ \\
\hline 10:D10S677 (119) & Late & Residual/AAO-AAE & 119 & $1.2 / 1.4$ \\
\hline 10:D10S1237 (134) & Late & Residual only & 132 & 1.1 \\
\hline 12:D12S392 (170) & Early and mixed & Residual/AAO-AAE & $167 / 168$ & $1.7 / 1.7$ \\
\hline 19:D19S178 (67) & Total & AAO-AAE only & 71 & 1.2 \\
\hline 19:D19S178 (67) & Late & AAO-AAE only & 73 & 1.2 \\
\hline
\end{tabular}

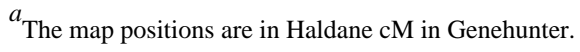

${ }^{b}$ Residual Model: The outcome is the residuals from a parametric, logistic survival model for age at onset of Alzheimer's Disease.

${ }^{c}$ AAO-AAE: The outcome is age at onset for affected persons and age at exam for unaffected relatives.

${ }^{d}$ MLS in bold are within $30 \mathrm{cM}$ of a peak found by the original genome scan of the NIMH dataset for AD risk [Blacker et al., 2003].
} 